\title{
Pioneer teachers: How far can individual teachers achieve agency within curriculum development?
}

\author{
Judith Kneen ${ }^{1}$ D . Thomas Breeze ${ }^{1}$ - Emma Thayer ${ }^{1}$ - Vivienne John ${ }^{1}$. \\ Sian Davies-Barnes ${ }^{1}$
}

Accepted: 13 September 2021

(c) The Author(s) 2021

\begin{abstract}
Education reform requires the commitment and investment of teachers if it is to succeed. Recognising the importance of teacher engagement, some countries have made teacher agency a feature of their curricula. Wales has embraced the notion of teacher agency within the building of its new curriculum by creating a body of Pioneer teachers to shape its new curriculum framework. This paper considers the nature of teacher agency experienced by a group of these Pioneers working on the expressive arts area of the curriculum. It does so through an exploration of the ecological nature of teacher agency, as theorised by Emirbayer and Mische (1998), and it considers agency through a framework of different levels: the micro-level focuses on the individuals and their personal contributions; the macro-level considers Pioneers' work at national level, liaising with teachers from across the country and taking responsibilityfor creating the curriculum; the meso-level refers to where the two former levels come together, i.e. the Pioneers' work within their own institution, trialling the new curriculum. The evidence indicates that teacher agency was easier to achieve at micro-level and macro-level, than at meso-level. This paper suggests, therefore, that achieving teacher agency at institutional level is more complex and challenging than is the case at the other levels. Greater understanding and attention are, therefore, needed about how to achieve teacher agency in teachers' different spheres of work, particularly when working at institutional level.
\end{abstract}

Keywords Teacher agency $\cdot$ Curriculum development $\cdot$ Expressive arts

\section{Abbreviations}

AoLE Area of learning and experience

GCSE General Certificate of Secondary Education

OECD Organization for Economic Cooperation and Development

Judith Kneen

judithkneen@btinternet.com

1 Cardiff School of Education and Social Policy, Cardiff Metropolitan University, Cyncoed

Campus, Cardiff CF23 6XD, UK 
PISA Programme for International Student Assessment

WG Welsh Government

\section{Introduction}

Curriculum change is dependent on teacher engagement because teachers are 'the ones who put reform ideas into practice' (Huizinga et al., 2014, p. 33). Indeed, successful implementation of curricular change relies on teachers' 'ownership' (ibid.) of the reforms and there is now a growing tendency to promote teacher agency as part of curriculum development, allowing teachers to have an 'active contribution to shaping their work and its conditions' (Priestley et al., 2015, p. 1). A review of teacher education in Scotland envisaged the teaching profession as being driven not by 'external forces of change' but instead regarding teachers 'as prime agents in that change process' (Donaldson, 2010, p. 14). As architect of the new Welsh curriculum, Donaldson has transferred this perspective into an underlying principle of curriculum reform in Wales by 'encouraging appropriate ownership and decision making by those closest to the teaching and learning process' (Donaldson, 2015, p. 14). These new curricula expect more from teachers than just 'delivering' the curriculum; rather, teachers are expected to be shaping and influencing the curriculum.

In Wales, selected teachers, known as Pioneer teachers, have been 'charged with building the new curriculum framework and designing and leading the professional development that will support all schools to realise it' (Welsh Government, 2015, p. 1). Agency is being expected of these teachers, in a way that has not happened since before the introduction of a national curriculum in Wales over thirty years ago.

Agency within an educational context has been well explored by Priestley et al. (2015), drawing on the seminal work of Emirbayer and Mische (1998, p. 962) who conceptualise agency as temporal and ecological in nature. This view presents agency not as a personal capacity — that is, 'something that individuals have or don't have' (p. 34) - but rather as something that is achieved by an individual, dependent on their context. This ecological model of teacher agency acknowledges the interplay between an individual and their environment. Within this study, we consider the Pioneer model of teacher agency in the light of this concept of teacher agency, and we do this within a micro- meso- macro- structure developed from Bronfenbrenner (1979).

Our study provides a perspective on what agency looks like for one group of Pioneer teachers: those developing the new curriculum for the expressive arts. It explores the experiences and perspectives of approximately half of these Pioneer teachers, providing important insight into the nature of agency within the Pioneer process. Whilst the study focuses on expressive arts Pioneers, our study addresses areas such as professional context and background, working relationships across traditional boundaries, and their ability to effect change. Such areas are not particular to the expressive arts, and so it is not unreasonable to consider that they may have relevance more widely across the curriculum. Furthermore, the approach to 
curriculum development in Wales is an innovative one and, as such, is of interest beyond the borders of Wales.

\section{What is teacher agency?}

Bandura provides us with a psychological perspective: 'To be an agent is to intentionally produce certain effects by one's actions' (Bandura, 2018, p. 130). It focuses on the individual capacity, noting three key features of the concept: forethought (the ability of people to plan ahead and anticipate future needs or actions); self-reactiveness (the setting up of standards for self-management and self-government); and self-reflectiveness (whereby individuals reflect on their efficacy within a given situation) (pp. 130-131). It is a perspective that puts a heavy emphasis on agency being individualistic, self-driven, and reflexive. Eteläpelto et al., (2013, p. 61) turn to agency in a professional context where individuals or communities 'influence, make choices, and take stances on their work and professional identities'.

Within an education context, agency is often connected to the idea of identity (Day et al., 2006; Beauchamp \& Thomas, 2009) — a strong awareness of identity being associated with a heightened sense of agency. However, seeing agency through the lens of identity implies an emphasis on the individual qualities of a teacher. Priestley et al. (2015) move beyond seeing agency as a personal capacity or something inherent to an individual and see it rather as an 'emergent phenomenon' (p. 19) which arises through 'the interaction of individual 'capacity' with environing "conditions" (p. 22). Agency, therefore, is dependent on the situation and the circumstances that exist.

This contextual significance of agency is noted by others. Professional agency is regarded as 'a relational phenomenon' by Pyhältö et al. (2012, p. 100); rather than just being a quality centred on the individual, agency is embedded in the interactions within an educational community. Lasky (2005) proposes a sociocultural view of agency where teacher agency is shaped by the social interactions and the cultural structures that a teacher works within. Agency, therefore, cannot be divorced from the structures and systems that have shaped the individual. Structures such as subject departments are both 'an expression of agency' as well as structures that shape agency (p. 902).

If teacher agency is dependent on the context in which a teacher operates, then, it cannot be established by a teacher alone. Indeed, agency is bounded by a range of constraints, relating to the sociocultural context of teachers' environments such as the nature of the national frameworks, school cultures, and management structures, as well as resource limitations (Imants \& Van der Wal, 2019). Pietarinen et al. (2016) draw attention to how teacher agency changes, depending upon the context. They distinguish between a teacher working in a professional community, i.e. with colleagues and professionals, and working in the classroom. Development work is often targeted at teachers working in a professional community, but this professional agency may not be easily transferrable to the classroom (ibid.).

However, whilst the agency of teachers is prompted or constrained by their environment and conditions, teachers are not devoid of influence. They can interpret 
and 'enact' their school environment (Imants \& Van der Wal, 2019, p. 3) thereby positioning themselves within their setting. Teachers have choices, although these may be limited. And agency does not always lead to sought-for improvement. Faced with change, teachers can 'adapt, ignore or adopt' (Pyhältö, 2014, p. 305) reforms. Teacher agency may mean rejecting change and continuing with existing behaviours and strategies. Buchanan distinguishes between two types of teacher agency: 'stepping up' and 'pushing back' (2015, p. 710). The former refers to a teacher 'going above and beyond the perceived expectations of her role' whilst 'pushing back' is about resisting change (ibid.) Therefore teacher agency 'should not be treated a priori as a positive factor for reform and development' (Imants \& Van der Wal, 2019, p. 4). Within education, agency involves responsibility for both individual thinking and developments, and 'for the development of professional community' (Pyhältö et al., 2012, p. 100). Effective innovation requires that teachers take responsibility for change and that they have the agency to do so (p. 117).

Priestley et al. (2015) draw on the work on Emirbayer and Mische (1998, p. 962) who conceptualise agency as a 'temporally embedded process', informed by the past but with orientations towards the future and the present. Agency is predicated by what a teacher has already experienced, by their plans and aspirations, and it is bounded by the 'concrete' practicalities of the present (Priestley et al., 2015 p. 30). This ecological view of agency recognises the essential interplay of the individual within their environment: agency is something achieved rather than possessed.

Priestley et al., (2015, p. 30) embed the ideas of Emirbayer and Mische (1998) within a model (Fig. 1) that distinguishes between (a) the iterational aspect (individual history and experience), (b) the projective aspect looking to the future (shortterm and long-term objectives) and (c) the practical-evaluative dimension which considers cultural, structural, and material aspects such as resources and relationships that can affect agency. All of these aspects can shape or inhibit teacher agency.

Because teacher agency is dependent not only on the individual, but on the context in which the individual operates, we have chosen to examine the nature of agency, as experienced by a sample of Pioneers, through a framework developed by psychologist Bronfenbrenner (1979) who devised a view of a human development in relation to an individual's ecological environment (Fig. 2). This environment was conceived of as 'a set of nested structures, each inside the next, like a set of Russian dolls' (p. 3). At the centre is the individual and their immediate associations and influences, a setting described by Bronfenbrenner as the microsystem ( $\mathrm{p}$. 7). Different settings indicate different levels of interconnectness with the individual, moving outwards through mesosystems (where the individual participates) and exosystems (settings that influence but do not directly involve the individual), all of which go to make up the whole interconnected macrosystem (pp. 7-8).

In this study, we have considered Pioneer agency in relation to three main contexts:

- Micro-level: considering the Pioneer at the individual level, e.g. qualities, ambitions, fears, etc.

- Macro-level: focusing on the Pioneers' work of national and potentially lasting significance (curriculum design). 

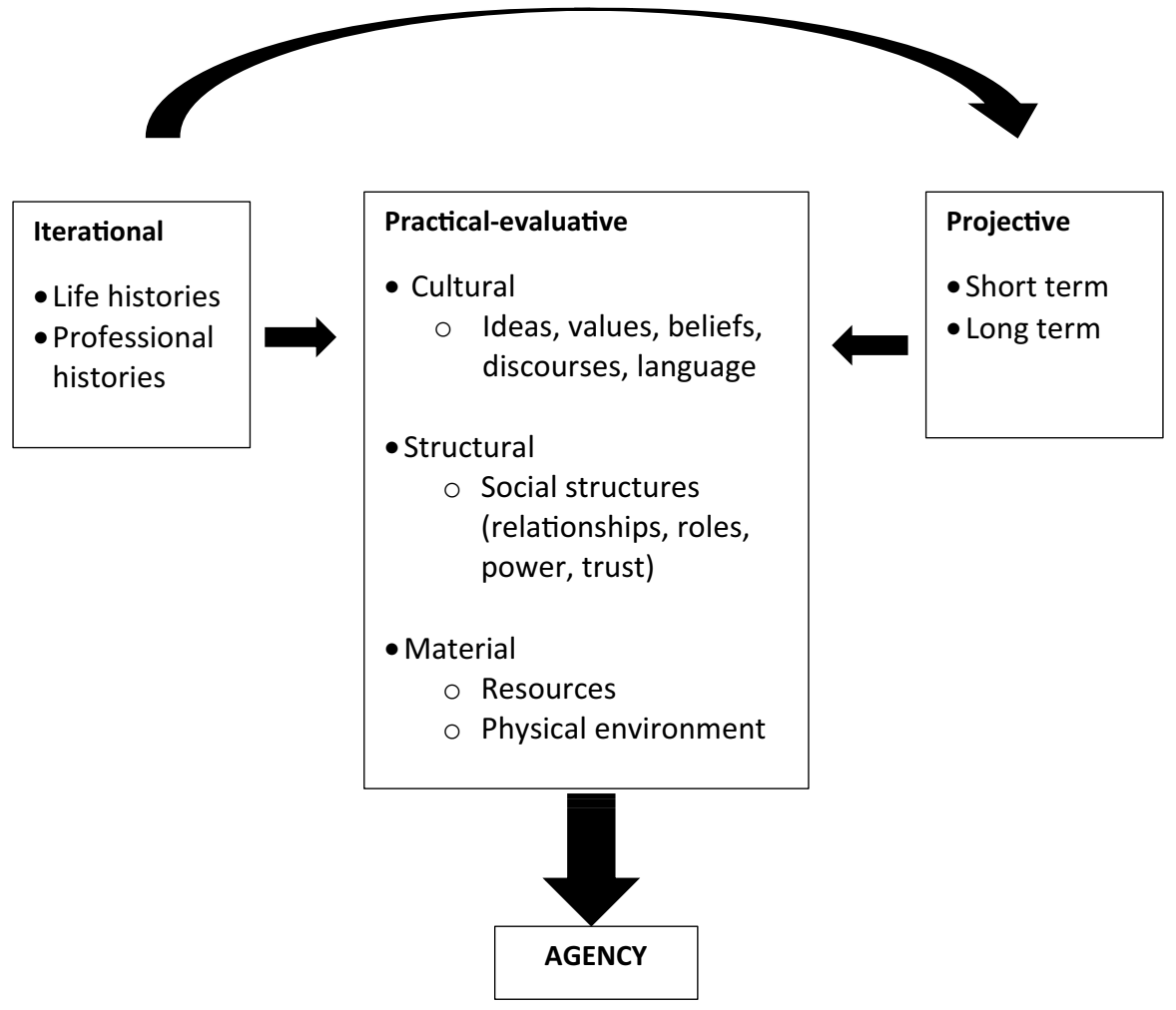

Fig. 1 Teacher agency model (Priestley et al., 2015, p. 30). This figure, taken from the text indicated, highlights the different influences on teacher agency. It indicates the significance of individual history (both personal and professional) and future plans and ambitions. Cultural, structural, and material aspects also support or constrain agency

- Meso-level: describing the Pioneers' work at local, institutional level, e.g. within their own department, school, or a neighbouring school.

This framework enables us to take a view of agency that goes beyond the individual and considers context more fully. Furthermore, it allows that teacher agency is not fixed but is 'highly relational' (Pyhältö, 2014, p. 307) and dependent on many variable factors.

\section{Pioneering a new curriculum in Wales}

Both politicians and the media have been critical of Welsh education in recent years spurred on by weaker examination results in comparison with other administrations in the UK and internationally (Power et al., 2020; Rees \& Taylor, 2013). Disappointing PISA results in 2009 (Bradshaw et al., 2010) sparked a focus on curriculum improvement in Wales and the commissioning of reports on the curriculum. 


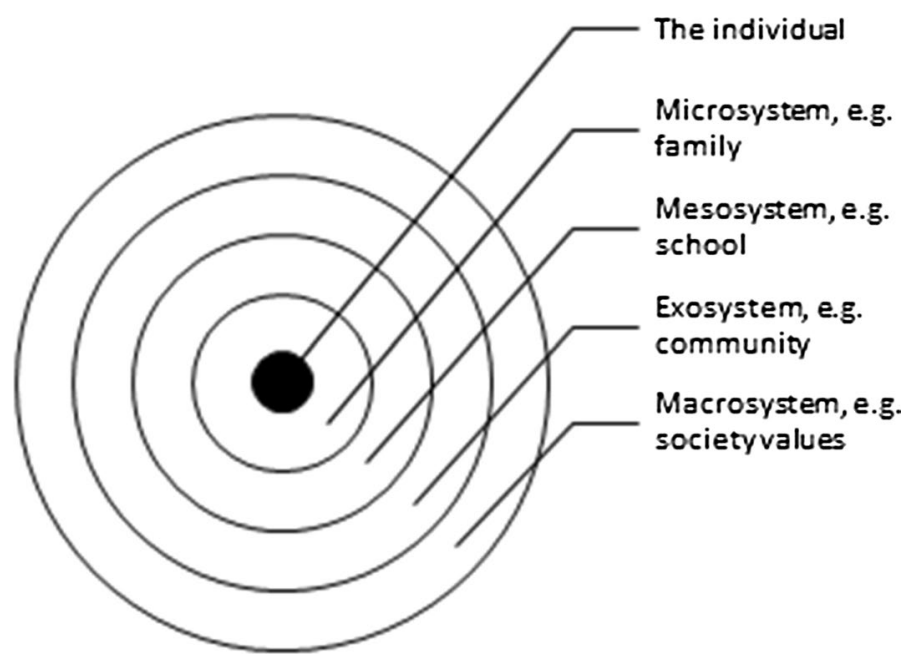

Fig. 2 Bronfenbrenner's ecological framework for human development. This figure is based on Bronfenbrenner's framework for human development. The individual is at the centre and those aspects of the individual's environment that have influence, are built up around the individual

The OECD (2014) reported on improving schools in Wales and highlighted four key principles, including 'Building professional capital and collective responsibility throughout the system'. A new curriculum was announced based on recommendations by Graham Donaldson in his Successful Futures report (2015). An incremental rollout is envisaged to take place, starting in 2022 (all pupils up to Year 7) and being completed in 2026 (up to year 11).

Donaldson's vision reflects international curriculum trends towards competenceled curricula (e.g. Education New Zealand Ministry of Education, 2015; Scotland, 2019) which aim to be 'lifelong learning systems in their own right', giving learners the ability to take up 'opportunities in fast twenty-first century waves of change' (Marope et al., 2017, p. 16). Marope (2013, p. 23) refers to the 'increased foresight and anticipatory capacity of curricula', which Donaldson calls 'future-proofing' the curriculum $(2015$, p. 33). In the new Welsh curriculum these competences are referred to as the Four Purposes (Welsh Government, 2019).

Donaldson noted that past and existing structures have stultified the capacity of teachers to act with independence, flexibility, and on behalf of pupils' needs:

For many teachers and schools the key task has become to implement external expectations faithfully, with a consequent diminution of local creativity and responsiveness to the needs of children and young people. (Donaldson, 2015, p. 10)

Donaldson was noting the tendency, within Wales and elsewhere, for teachers to merely convey a curriculum they had little influence over and to 'deliver policy, deliver learning outcomes, deliver curricular entitlements' (Priestley \& Philippou, 2018, p. 153). In the case of the Welsh curriculum, Donaldson encouraged 'appropriate ownership and decision making by those closest to the teaching and learning process' (2015, p. 14). 
This call for subsidiarity led to the introduction of Pioneer practitioners-a network of teachers selected to develop the new curriculum framework (Welsh Government, 2015). The Pioneers were chosen as being innovative practitioners and those who have made a distinct contribution to curriculum. Funding was allocated to their schools to support the Pioneers.

A key responsibility of the Pioneer teachers has been to create the curriculum framework. Following curriculum patterns developed in countries such as New Zealand and Scotland, the new curriculum is structured into of the Areas of Learning and Experience (AoLEs) (WG, 2019). In Wales there are six AoLEs:

- Expressive arts

- Health and well-being

- Humanities

- Languages, literacy, and communication

- Mathematics and numeracy

- Science and technology.

The curricular framework for each AoLE has been developed by a group of Pioneers from primary, secondary and special schools. The schools in which Pioneers were employed have been funded to allow Pioneer teachers to devote two days per week on developing the new curriculum. This includes two days each month to meet with other Pioneers. An evaluation of the Pioneer model, commissioned by Welsh Government (WG), noted that schools in which Pioneers worked developed a commitment to Donaldson's vision, but there were issues, particularly in the early stages of their work, relating to the clarity of their role and to ensuring coherence and consistency across schools (Arad Research and ICF Consulting, 2018). More importantly, the evaluation recognised that whilst schools in which Pioneers were employed were on board, most of the schools in Wales were not and so 'more concerted action and engagement with all Partner Schools throughout Wales' (p. 6) was needed. A possible implication here, is that the creation of a body of Pioneer teachers to shape the new curriculum had the effect of making the remaining schools feel excluded from the reforms.

This paper draws from a study of the Pioneer experience within the expressive arts AoLE conducted in the summer of 2018. It explores the nature of agency within the context of developing the expressive arts AoLE, a grouping that includes the following traditional subject areas: art, dance, drama, film and digital media, and music. However, whilst the immediate context of our study is the sphere of the expressive arts, the broader context is curriculum development within a national setting and so we believe that the findings will resonate with other areas of the curriculum where curriculum development is sought.

\section{Methodology}

This paper emerges from a study examining the perspectives of Pioneer teachers in the expressive arts. It focuses on the lived experience or 'life world' (Flick, 2014, p. 12) of Pioneer teachers. In order to gain insight into the Pioneer experience, we 
adopted a qualitative approach with two main data collection methods: (1) interviews with Pioneer teachers and (2) observations of the Pioneers as they worked within their Pioneer group. Whilst our study explored a range of areas (e.g. curriculum integration, and primary and secondary experiences of being a Pioneer), this particular paper considers our focus on the role of Pioneer teacher in relation to teacher agency where we sought to utilise the Pioneers' perspective to explore the nature of the agency achieved by the Pioneer teachers as well as the constraints they experienced.

\section{Interviews}

At the time of the study, the expressive arts Pioneer group consisted of 19 teachers, representing 8 primary schools, 8 secondary schools, 2 special schools, and 1 through school (both primary and secondary on one site). Schools across Wales were invited by WG to bid to become a Pioneer school. If successful in their bid, the headteacher then nominated or invited suitable teachers to take on the role of Pioneer teacher. Some schools or individuals with a record of good practice in a specific area of the curriculum were encouraged to enter the bidding process. There were also a number of additional members (e.g. representing WG, Estyn ${ }^{1}$ and Qualifications $\mathrm{Wales}^{2}$ ) to provide leadership and support to the group. The sample chosen for this study consists of eleven teachers from the Pioneer group, so just over half of the total group. The interviewees were selected through purposive sampling with the 'research goals in mind' (Bryman, 2016, p. 408). Whilst the sampling aimed to broadly reflect the range and types of Pioneer teachers engaged in the AoLE group as a whole, it was also deemed important to gain representation from the different administrative authorities in Wales, as well as English, bilingual, and Welshmedium schools. The final sample included interviewees from primary, secondary, and special schools (Table 1) across Wales, representing bilingual, Welsh-medium and English-medium schools.

A semi-structured framework of questions was devised to support the interviews which lasted from 45 to 60 minutes and sought to to capture the individual experiences of each of the Pioneers-their 'voices and stories' (Hennink et al., 2011, p. 110). Questions were arranged in sections to collect data about a range of areas, including their background and teaching experience, their Pioneer experiences within different contexts, the impact of their work on their own school's curriculum, and their hopes and fears for the new curriculum. The semi-structured interview framework encouraged a flexible dialogue which allowed interviewees the opportunity to focus on areas of importance for them. The interviews took place from May to July 2018, and interviewees were given the choice of having the interview in English or Welsh.

\footnotetext{
${ }^{1}$ Estyn is the organisation that provides inspections and guidance on education quality and standards in Wales.

${ }^{2}$ Qualifications Wales is the body responsible for the regulation of qualifications (other than degrees) in Wales.
} 
Table 1 The Pioneer teachers who were interviewed

\begin{tabular}{clll}
\hline Type of school & \multicolumn{2}{l}{ Teachers (pseudonyms used) } \\
\cline { 2 - 4 } & Name & Age range & Years in teaching \\
\hline Pioneers from & Bronwen & $50+$ & $30+$ \\
primary and & Charles & $50+$ & 12 \\
special schools & Delia & $40-50$ & 20 \\
& Francis & $20-30$ & 6 \\
& Harriet & $30-40$ & 13 \\
& Jenna & Not available & Not available \\
Pioneers from & Kim & $40-50$ & 21 \\
secondary & Ashley & $30-40$ & 13 \\
schools & Elaine & $40-50$ & 22 \\
& Gina & $30-40$ & 15 \\
& Iona & Not available & Not available \\
\hline
\end{tabular}

This table lists the Pioneer teachers who were interviewed. All the names are pseudonyms. They came from a range of school types. (Subjects are not given for the secondary teachers, due to the small population involved, and the risk of losing anonymity.)

\section{Observation}

The Pioneer teachers met as a group for two days every month, when they worked together on creating the curriculum framework. Part of the study was to observe the Pioneers at work in these meetings so that they could be observed 'in their temporal and local particularity' (Flick, 2014, p. 22) and to see how things 'normally happen' (Denscombe, 2017, p. 225). Observing the group working together would also help to triangulate data from the interviews. Having gained the agreement of the leader of the AoLE group, a researcher attended three days of meetings. In the initial meeting, the researcher addressed the whole group to explain the research and to ask for individuals' consent to be involved. Once consent had been obtained, the researcher proceeded to observe the group at work.

\section{Analysis}

Both deductive and inductive coding (Hennink et al., 2011, p. 210) were used to analyse the interview data. Deductive coding derived from the main research instrument (the semi-structured interviews) led to the initial categorisation of responses, including the following areas:

- How they came to be Pioneer teachers

- What the role of Pioneer teacher entailed

- How others responded to their role

- The positive aspects and challenges of the role 
- The impact of their work on the emerging curriculum

Inductive coding, which allows the data to 'speak for itself' (p. 218), emerged from the data in the form of the ideas and issues raised by the participants themselves, including:

- Affective responses (e.g. their feelings about being a Pioneer)

- Changes in professional outlook and development

- Professional relationships (e.g. with peers and managers)

The initial broad range of codes was refined to a more limited set of themes which included Pioneer experiences, effectiveness, and curriculum impact. Qualitative data analysis software was used to help support the exploration of the themes and to draw out a more nuanced scrutiny of the data. For example, a theme of pioneer effectiveness was established; further exploration of this theme led to a range of 'subthemes', including Pioneer perceptions of the role, challenging aspects of the role, supportive aspects, Pioneer ambitions, and key requirements for change. Consistency between the research team was achieved through initial coding activities and meetings as a team (to establish the coding framework), followed by joint coding of interviews in pairs, and regular meetings to share and discuss the ongoing analysis. Data gathered in the form of fieldnotes during the observations also helped to inform and triangulate the data gathered from the interviews.

\section{The nature of Pioneer agency}

The Pioneer model is an innovative approach which represents 'a commitment to empower and support teachers to develop the new curriculum' (Arad Research \& ICF Consulting, 2018, p. 5). Here we aim to consider aspects of the nature of agency afforded by this model, and we do this through an exploration of the experience of selected Pioneer teachers. We have employed the ecological model devised by Priestley et al. (2015) to consider the agentic nature of their role (Fig. 1). This model takes account of the iterational aspects of the Pioneers' work (e.g. their professional history), the practical-evaluative dimension of Pioneer engagement (e.g. how their current context impacts on their Pioneer work) and the projective aspect of their work (e.g. their hopes for the impact of their Pioneer work). The capacity for agency results from 'the interplay of individuals' capacities and environment conditions' (Priestley et al., 2015, p. 3) and so we have structured our findings and discussion by considering the micro-, meso- and macro-level factors that shape their capacity for agency (Pantić, 2017, p. 221). This 'interplay' means that it can be difficult to tease apart different aspects that may be dependent on each other, or fit comfortably within more than one factor, but this approach emphasises the importance and influence of different contexts in terms of achieving agency within the sphere of education reform. Education leaders and policy makers who invoke teacher agency as part of curriculum reform need an understanding of the complexity of teacher agency as well as the complexity of interplay in different contexts. 


\section{The Pioneer role at micro-level}

By micro-level, we refer to the individual, personal factors that help to shape agency such as personal experiences, values, ambitions, and feelings. This largely iterational dimension of agency (Priestley et al., 2015) describes what the Pioneers brought with them to the role. The Pioneer teachers worked as a group, but the Pioneer process brought together individual teachers from a range of backgrounds and educational contexts. The individual professional experience and backgrounds teachers possess are significant as 'agency doesn't come from nowhere but builds upon past achievements, understandings and patterns of action' (ibid., p. 24).

Schools across Wales were invited by WG to bid to become a Pioneer school. If successful in their bid, the headteacher then nominated or invited suitable teachers to take the role of Pioneer teacher, as in the case of primary school teacher, Delia:

I was approached by the head, who asked if I would be willing... he knew I'm interested in things like this anyway, so I was more than happy to jump on board.

Some schools or individuals with a record of good practice in a specific area of the curriculum were encouraged to enter the bidding process. Secondary teacher Iona recalls that the local Consortium ${ }^{3}$ enquired whether she would be interested in being a Pioneer:

"Do you think Iona will be interested and apply to be Pioneer for the Expressive Arts?" Then I said yes and there was no turning back after that.

The professional backgrounds and contexts of teachers from primary and secondary schools were very different. When interviewed, the secondary school teachers always identified themselves initially by their subject specialism. Unlike secondary Pioneers, who were likely to have a degree in their teaching subject, primary teachers often had no formal qualifications in the arts, and they did not perceive themselves as having subject expertise:

I'm not an artist, I'm not an expert—and I've said this to the Pioneer staffbut I like art. (Charles)

I didn't even do expressive arts at GCSE... (Harriet)

The idea of expertise was repeatedly referred to:

...we're not experts at the art, music, we're not experts in that, but we have to have a knowledge of it to teach it. (Francis)

They're [secondary teachers] the knowledge experts, and the primaries are the pedagogy experts. (Charles)

\footnotetext{
${ }^{3}$ Consortia are the organisations that work on behalf of local authorities in Wales to provide a school improvement service. There are four consortia.
} 
Francis and Charles, both primary school teachers, here provide a justification of their inclusion as a Pioneer teacher in a way that the secondary teachers did not do. Indeed, some primary Pioneers spoke of being intimidated by the experience at first:

I was a little bit feeling out of my depth, like, what would I possibly contribute to this group? (Delia)

Delia's initial unease was supplanted as their Pioneer work progressed:

But, actually, it's been valuable for me to learn from the specialists, but it's also been valuable for the specialists to learn from the practitioners who are not specialists.

Her sense of agency and value was boosted by the realisation of what she could contribute to the process. Whilst the Pioneers from secondary schools brought in subject knowledge of a particular area of the curriculum, the primary teachers contributed through their experience of a specific pedagogic approach. They had far more experience in working within an integrated curriculum, an approach espoused by Donaldson (2015). The primary teachers were familiar with employing a thematic teaching and learning model, where a theme is used to arrange the teaching of curriculum areas rather than teaching through subjects as happens in secondary. This thematic approach is a significant introduction to the new curriculum in Wales (Kneen et al., 2020) and so this experience on the part of primary colleagues proved a valuable area in which they could contribute to the development of the Pioneer group's work.

Both primary and secondary Pioneers sought valorisation within the Pioneer group. Understanding their own experience and capacities, and recognising that that experience was relevant and valuable, was a significant step towards achieving agency for these teachers.

As well as their background experience, the Pioneers' affective outlook proved an influential factor. Both primary and secondary teachers felt very fortunate to be Pioneers. Being put in this position of agency was highly unusual; they had not had previous experience of this, and they ascribed their involvement to good fortune.

I think we've been given a gift. (Elaine).

How lucky am I to be involved in this process? (Kim)

[we are] lucky that we're actually involved, whereas other schools are outside that loop... (Charles)

...not everybody's a Pioneer school; we are very lucky to be selected. (Delia)

They find their experience of this agentic role is unusual and numerous references to luck indicate being in a position of privilege, particularly in relation to other schools, but also within their own schools:

This, being a Pioneer, it just gives you this freedom to research, to engage with a higher level of thought and professional dialogue, but it's constantly remembering that you're one of the lucky ones in that way; your colleagues back at school don't have that time freedom to do it. (Gina) 
Gina highlights these features which are part of an agentic role-research, reflection, and professional dialogue — as freedoms that are not generally considered aspects of school life for teachers; they are not part of the professional history that the teachers have brought to the Pioneer group. Their perception is that their new agentic role is something extraordinary and exceptional. Their appreciation of their luck is tempered by the awareness that not everyone has this opportunity.

The Pioneers were consistent as individuals in terms of the strong sense of engagement and positivity they brought to the Pioneer group work:

It's been incredibly interesting and enjoyable, and I suppose that it's reinvigorated my enjoyment for the job. (Ashley)

We do feel proud of the opportunities that we're providing the children with. (Delia)

I'm very proud to be part of the process. It is interesting and exciting. (Jenna)

Eight of the eleven respondents used the word 'exciting' to describe involvement in the process. The work was demanding but they were positive about the nature of the reform and their contributions. They clearly felt that their work was of value and that learners would be the beneficiaries. The teachers were aware of the responsibility and import of their role:

I'm writing the new curriculum for expressive arts. (Harriet)

In explaining her role as a Pioneer teacher, Harriet's use of the first-person singular emphasises her own individual responsibility both within the group and to the wider educational establishment.

At the micro-level, then, the Pioneer teachers generally brought great positivity and ambition for the work, which might be expected from a group of teachers that were selected to be part of the process because of their interest or experience in the area. They found themselves having to establish their area of expertise or value in order to justify their position in the group. This was particularly the case for those primary Pioneers who had no subject qualifications in the arts. The Pioneers were also aware of the import of their work and the influence it would have. All of these aspects helped to bring about a sense of agency within the individuals concerned. They took pride in their work and recognised the personal responsibility they were taking in creating the new curriculum.

However, it was not just what they brought to the group as individuals that enabled them to work together. It was also their ability to learn from others in the group. The primary and secondary Pioneers brought different professional perspectives to their Pioneer group. They had to learn from each other in order to move forward; they had to develop their understanding and possibly adjust or change their thinking on areas. Such individual qualities were central to their capacity to contribute to Pioneer work at macro-level. 


\section{The Pioneer role at macro-level}

By macro-level, we refer to Pioneers' work within their widest sphere, that is, their work at national level, working with colleagues from schools across Wales and from national organisations such as Estyn. Their curriculum development work in this context was of national and long-term significance. Macro-level activity was central to the work of the Pioneers; their raison d'etre was to devise a section of the new curriculum for Wales. The Pioneers worked with a wide group of professionals, including subject specialists and other professionals invited in by WG to support the group. There was a strong 'projective' (Priestley et al., 2015, p. 30) aspect to their work, with short-term and long-term goals for their work together. However, it was the 'practical-evaluative' (ibid.) aspects (e.g. cultural and structural matters) that impacted on the ability of Pioneers to exercise agency at the macro-level, in particular relationships and values.

Pioneers were expected to devote two days per week to their Pioneer work, including attending a two-day meeting every month where the Pioneer teachers from different contexts (special schools, primary schools, secondary schools and English and Welsh-medium schools, and bilingual schools) convened to work on the curriculum framework. There were around 20 people in the meetings and the interviews revealed that they did not 'gel' at the start of the process. Their different iterational perspectives (Priestley et al., 2015) came to the fore early in their work:

As an AoLE, we were just horrendous. We were all, 'I am a music teacher. I am an art teacher. This is just ridiculous.' (Gina)

As has already been noted, the Pioneers had to establish their validity to be in the group, e.g. their level of expertise. By the time the group were observed for this study they had clearly grown used to working with each other and certain members of the group took on particular unofficial roles, such as reminding the group about possible Welsh translation needs and ensuring that pupils with special needs were part of their considerations. Generally, those who were subject specialists spoke up for their subjects, ensuring that subject-specific elements were not overlooked in their deliberations. Observations showed effective working relationships, and some Pioneers had even visited each other's schools to share professional ideas.

Some of the Pioneers found working in a large group of around 20 people challenging, as some Pioneers were perceived as very vocal and other members of the group perhaps felt frustrated:

You have some very strong characters; very strong, very discipline-driven characters who are quite overpowering. (Harriet)

Working in a large group also had drawbacks in terms of establishing the direction of the work:

I think because of the work that we've actually been doing, there hasn't necessarily been a right answer. I think sometimes, we've wanted people to say, 'Well, can you just do this?' but no one actually knows what the 'do this' is. I think that's been frustrating, and that's been tricky sometimes. (Harriet) 
The pace of work was also frustrating for some. Their work was reviewed by the Curriculum and Assessment Group, a group convened to provide feedback and guidance to Pioneer groups. The feedback often meant them revisiting aspects of their work:

When you come in and sort of feel, 'Right, we know what we're going to do today. We were told last time we're having to do, progression steps,' and we come back in and they go, 'Oh no, no, we're not doing that. We have to reword the "What Matters" statements again.' And we're going, 'But we've done that fifteen times already'. (Elaine)

The work might have been frustrating at times due to the numbers in the group and the pace of progress, but the Pioneers established areas of commonality that supported their perception of achieving agency at this macro-level. They first ascertained the links between the traditional subjects within the AoLE:

We've developed our three pillars, which underpin the whole of the expressive arts curriculum, which is to explore and experience, create and express, and also respond and reflect. (Ashley)

Establishing cohesion was important in supporting the Pioneers' progress and they returned to these foundational tenets when they found progress was uncertain. A further factor was their commitment to supporting the development of the arts in schools. The arts have been significantly marginalised within the curriculum in recent years as core subjects (English, mathematics, science) and STEM subjects (science, technology, engineering, and mathematics) have been prioritised (Hennessy et al., 2001; Oelkers \& Klee, 2007). The Pioneers' commitment to teaching the arts is encapsulated by Kim's assertation 'I am expressive arts'. She brings together 'iterative', 'projective' and the 'practical-evaluative' elements of the Teacher Agency Model (Fig. 1) in a statement that encapsulates personal commitment, professional values, and ambition.

The Pioneers also expressed concerns about the impact and longevity of their work. A commonly expressed fear was that of other teachers (in their own school or other schools) not understanding and acting on the reforms. Jenna sums this up when she says that colleagues in schools may:

...try to fit the old things they have always done into the new curriculum and try to do the same things and not really change their practice.

No change in practice is what the Pioneers feared most. Jenna realises that provision of a curriculum framework is only part of what is needed.

Teachers' mindset needs to change before they are really ready to accept the new curriculum. Therefore, there needs to be a lot of learning and professional training I would say in schools rather than it arriving cold. (Jenna)

Jenna recognises that, similar to the Pioneers, other teachers will require professional opportunities to develop their thinking and establish "collective 
sense-making' (Bridwell-Mitchell, 2015, p. 142) in order to develop the new curriculum framework in their own context.

\section{The Pioneer role at meso-level}

Within this study, meso-level refers to the Pioneers' work at their local, institutional level, so working within their own school (and departments in the case of secondary schools). Their work at meso-level involves the interplay between micro- and macro-level work and references each of the main aspects described by the Teacher Agency Model: iterational, practical-evaluative and projective (Fig. 1). Importantly, it indicates whether individual Pioneers can translate the developments planned at macro-level into change at school level.

The Pioneers' capacity for agency at meso-level was influenced by two key factors:

- School management

- The response of their peers/teachers.

\section{School management}

The school management strongly influenced the Pioneers' agentic capacity. In some cases, mostly in primary schools, the headteacher was praised as being highly supportive of the process:

The head is brilliant; he gives us time to work with our year-group partners where we'll be able to plan the following term coming up, which expressivearts projects so we can try and undertake for the children. (Delia)

The Pioneers identified supportive management actions such as:

- Providing time and funding to enable people to come together

- Allowing Pioneers to test things out

- Providing curriculum time for expressive arts

- Supporting the development within the local community of schools

- Supporting professionals coming in to work with teachers

However, managing the Pioneers' work in school was not always straightforward. WG funded each school to facilitate this work, including funding for teacher supply cover (i.e. substitute teachers) for two days per week. Despite this funding, Pioneers did not always find it easy to secure the required time. When the first tranche of funding came into schools, it was too late for schools, within the current year's timetable planning, to employ a teacher on a fractional timetable to cover the Pioneer teacher's two days. Consequently, short-time supply cover was used, which proved difficult for a number of reasons: 
Initially in the first year, I had to have supply in, which was not ideal, because you have to plan for them, so you're sort of teaching, but you're not teaching, and picking up all the issues that you get with supply. (Charles)

In the case of short-time supply cover, the teacher still needs to plan the teaching workload for the supply teacher, and also to manage the classroom issues that may arise. So, as Charles points out, for those two days, the Pioneer teacher has a dual role of overall responsibility for their class(es) as well as their Pioneer work. Once proper cover was provided, things improved for some teachers:

The first 12 months, I felt like I was leaving classes, whereas now, my timetable this year has been set for the two days a week, I've managed to do far more. I'm using the time effectively as well. (Iona)

However, effective cover was not always provided:

I'm released for the time that I need to be released in order to be able to complete the work. I don't take every single two-days-a-week. (Ashley)

I've done as much as I can with the time I've been given. I've gone to most conferences, but because of my exam commitments to upper-school classes, obviously, there was a period of time last year where even there were some parents who weren't happy with the amount of time I would be out of school, so I've been mindful of that this year, made choices of where my time needs to be. (Elaine)

For these teachers, their teaching role took precedence with Pioneer work fitting around it, even though funding was provided for supply. The imperative of preparing examination classes was a particular obligation for Pioneers working in the secondary sector. Whilst it might appear that it is the individual teacher taking the decisions here, a closer look at the language reveals that the school management is the decision-maker. The use of the passive voice ('I'm released', 'the time I've been given') indicates these decisions most likely lie not with the teacher but with school management.

The Pioneer teachers relied on school management to support activities such as information sharing, leading development sessions, trialling strategies in school, and working with local clusters of schools. However, existing school cultures were not always supportive. One secondary Pioneer recalled being asked by a neighbouring school to provide input on the expressive arts AoLE but her headteacher refused her permission as 'we don't go sharing with our rivals'. Pioneer teachers were being asked to facilitate a culture of change, but their capacity to do this could be halted by the existing culture of rivalry and competition between schools. Schools and teachers have been subject to a 'high-stakes accountability' culture over the past two decades (Holloway et al., 2017, p. 3). Consequently, secondary schools, in particular, are sensitive to the impact on terminal assessments (e.g. GCSEs exams for 15-16 yearolds) through which they are judged. The Pioneers were unaware of the potential changes there might be to future examinations in response to the new curriculum. Gina expressed optimism about any changes, but her call to be 'brave and 
bold' about changes to the qualifications, recognises the concern about risk in this area.

\section{Pioneer peers}

Another key factor impacting on agency at meso-level was the response of the Pioneers' school colleagues. Charles recognises the significance of influencing other teachers:

It doesn't matter how many words we put down or how glossy it is and what picture format, font. It's about teachers. If they believe in it and they agree with it and they want to do it, that's when it's going to change.

Within the primary schools, there was more confidence of a positive response:

Primary colleagues will just grab it with two hands. (Bronwen).

Primary teachers' confidence arises from their familiarity with the cross-curricular approach promoted by the AoLE work:

We're lucky because we teach topic-based all the time, so we're used to intermingling all of the subjects. (Delia)

The secondary Pioneers were less likely to receive a positive response. The cross-curricular approaches are generally far more challenging for secondary schools where content is usually taught in discrete subjects. Initial reactions from their peers could be daunting, exemplifying the assertion of Pietarinen et al. (2016) that agency established within one context (i.e. the Pioneer group) may not easily be transferrable to another. Here Gina reflects on how her colleagues at school responded to her Pioneer work:

That was scary realising there was absolute negativity. 'Why on earth have we got to change? We're working to capacity.'

Gina's peers exerted their own agency by 'pushing back' (Buchanan, 2015, p. 710). Her difficulty in engaging colleagues in her school, points up a shortcoming in the Pioneer process:

You're building capacity in maybe one person, assuming it's across a Pioneer school, when, actually, it doesn't necessarily mean there's an appetite.

In terms of the Teacher Agency Model (Fig. 1), it proved very difficult for some of the Pioneers to overcome the existing cultural and structural facets of the school. 'Reform implementation is influenced by collective sense-making' (Bridwell-Mitchell, 2015, p. 142) and this was not always achieved within the Pioneers' institutions. 


\section{Conclusions}

Within this paper, we have considered agency as an ecological phenomenon, which is achieved rather than being an individual 'capacity' (Priestley et al., 2015 , p. 22) that we possess. The nature of agency is dependent on context and is determined through the interplay of such aspects as experiences, circumstances and relationships. In order to explore the impact of such aspects, we have used a structure, developed from Bronfenbrenner's ecological framework (Bronfenbrenner, 1979), which considers the contextual factors at micro-, macro- and mesolevel. Framing the discussion using frameworks from both Priestley et al. (2015) and Bronfenbrenner (1979) has enabled a nuanced consideration of how the Pioneers' agency differed according to the different contexts within which they worked.

At micro-level Pioneer teachers were chosen because of their past experiences, indicative of the iterational dimension of agency (Priestley et al., 2015). Confidence in their Pioneer role arose from establishing their area of competence; with a recognised area of expertise, they felt able to be agentic. They were also emotionally engaged with the Pioneer work, feeling excited and fortunate to be engaged in the work. Significantly, in terms of agency, the Pioneers adopted personal responsibility and ownership of their work.

The Pioneers' agentic engagement at macro-level was also clear, and resonated with the 'projective' and 'practical-evaluative' aspects noted by Priestley et al. (2015). Despite initial difficulties and some frustrations, e.g. with pace, as a group they were able to create the curriculum framework for the expressive arts. Establishing a commonality of perspective, e.g. through their commitment to the arts, was important in helping the group 'gel' and to form the collective approach needed for reform. The sociocultural dynamic (Lasky, 2005), provided by structure, resources and cultural reinforcement, supported the Pioneers' agency at macro-level.

Achieving agency at meso-level was less clear-cut, highlighting that agency in one context does not necessary transfer to another (Pietarinen et al., (2016). Work at meso-level touches on all aspects of the Teacher Agency Model: iterational, practical-evaluative and projective (Fig. 1). Cultural and structural factors in schools were particular influential factors. In primary schools, change tended to be more holistic and easier to achieve. With a smaller staff and, therefore, a more involved headteacher, it appeared easier to translate their AoLE developments to their own context. Familiarity with teaching thematically, made the model of an AoLE approach easier to understand and implement. Secondary schools, however, are larger organisations, organised by subjects and have less timetabling flexibility. A culture of accountability, driven by the imperative of terminal examinations, sometimes led to a cautious and rather negative attitude which inhibited Pioneer agency.

The Pioneer approach is innovative in that WG are encouraging teachers as agents who 'shape the implementation of reform' (Bridwell-Mitchell, 2015, p. 141), an approach which is 'more demanding of the teaching profession' (Power 
et al., 2020). However, Priestley and Minty (2013) note that whilst developing the capacity of individual teachers is an important contribution to developing curriculum policy, raising the capacity of individuals is simply not enough. It 'also requires change to the structural and cultural conditions within which teachers work' (p. 50). This study confirms that developing teachers as agents of change requires more than the development of individual teachers. Leaders of curriculum reform need to fully understand and address the operation and interplay of agency in different contexts, particularly at institutional level, where structural and cultural facets of a school can make or break effective reform if 'meaningful educational practice' is to transpire (Priestley et al., 2015, p. 164).

Acknowledgements The research was supported by funding from HEFCW (Higher Education Funding Council for Wales) and the Wales Institute of Social and Economic Research and Data (WISERD).

Open Access This article is licensed under a Creative Commons Attribution 4.0 International License, which permits use, sharing, adaptation, distribution and reproduction in any medium or format, as long as you give appropriate credit to the original author(s) and the source, provide a link to the Creative Commons licence, and indicate if changes were made. The images or other third party material in this article are included in the article's Creative Commons licence, unless indicated otherwise in a credit line to the material. If material is not included in the article's Creative Commons licence and your intended use is not permitted by statutory regulation or exceeds the permitted use, you will need to obtain permission directly from the copyright holder. To view a copy of this licence, visit http://creativecommons.org/licen ses/by/4.0/.

\section{References}

Arad Research \& ICF Consulting. (2018). Formative evaluation of the Pioneer School model: Final report. Cardiff: Welsh Government, GSR report number 47/2018.

Bandura, A. (2018). Toward a psychology of human agency: Pathways and reflections. Perspectives on Psychological Science, 13(2), 130-136.

Beauchamp, C., \& Thomas, L. (2009). Understanding teacher identity: An overview of issues in the literature and implications for teacher education. Cambridge Journal of Education, 39(2), 175-189.

Bradshaw, J., Ager, R., Burge, B. \& Wheater, R. (2010). PISA 2009: Achievement of 15-year-olds in Wales. Slough: NFER.

Bridwell-Mitchell, E. (2015). Theorising teacher agency and reform: How institutionalized instructional practices change and persist. Sociology of Education, 88(2), 140-159.

Bronfenbrenner, U. (1979). The ecology of human development: Experiments by nature and design. Cambridge. Harvard University Press.

Bryman, A. (2016). Social research methods (5th Edn.). Oxford: Oxford University Press.

Buchanan, R. (2015). Teacher identity and agency in an era of accountability. Teachers and Teaching: Theory and Practice, 21(6), 700-719.

Day, C., Kington, A., Stobart, G., \& Sammons, P. (2006). The personal and professional selves of teachers: Stable and unstable identities. British Educational Research Journal, 32(4), 601-616.

Denscombe, M. (2017). The good research guide: For small-scale social research projects (6th ed.). Open University Press.

Donaldson, G. (2010). Teaching Scotland's future: Report of a review of teacher education in Scotland. Edinburgh: Scottish Government.

Donaldson, G. (2015). Successful futures: Independent review of curriculum and assessment arrangements in Wales. Cardiff: Welsh Government.

Education Scotland. (2019). What is curriculum for excellence? Retrieved May 14, 2021, from https:// education.gov.scot/education-scotland/scottish-education-system/policy-for-scottish-education/ 
policy-drivers/cfe-building-from-the-statement-appendix-incl-btc1-5/what-is-curriculum-for-excel lence/.

Emirbayer, M., \& Mische, A. (1998). What is agency? The American Journal of Sociology, 103, $962-1023$.

Eteläpelto, A., Vähäsantanen, K., Hökkä, P., \& Paloniemi, S. (2013). What is agency? Conceptualising professional agency at work. Educational Research Review, 10, 45-65.

Flick, U. (2014). An introduction to qualitative research (5th ed.). Sage.

Hennessy, S., Rolfe, L., \& Chedzoy, S. (2001). The factors which influence student teachers' confidence to teach the arts in the primary classroom. Research in Dance Education, 2(1), 53-71.

Hennink, M., Hutter, I., \& Bailey, A. (2011). Qualitative research methods. Sage.

Holloway, J., Sørensen, T. B., \& Verger, A. (2017). Global perspectives on high-stakes teacher accountability policies: An introduction. Education Policy Analysis Archives, 25(85). Retrieved April 23, 2020 from https://epaa.asu.edu/ojs/article/view/3325/1955.

Huizinga, T., Handelzalts, A., Nieveen, N., \& Voogt, J. M. (2014). Teacher involvement in curriculum design: Need for support to support teachers' design expertise. Journal of Curriculum Studies., 46(1), 33-57.

Imants, J., \& Van der Wal, M. M. (2019). A model of teacher agency in professional development and school reform. Journal of Curriculum Studies. https://doi.org/10.1080/00220272.2019.1604809

Kneen, J., Breeze, T., Davies-Barnes, S., John, V., \& Thayer, E. (2020). Curriculum integration: The challenges for primary and secondary schools in developing a new curriculum in the expressive arts. The Curriculum Journal. https://doi.org/10.1002/curj.34

Lasky, S. (2005). A sociocultural approach to understanding teacher identity, agency and professional vulnerability in a context of secondary school reform. Teaching and Teacher Education, 21(2005), 899-916.

Marope, M. (2013). Reconceptualizing and repositioning curriculum in the 21st century. Geneva: IBE UNESCO. Retrieved May 14, 2021, from http://www.ibe.unesco.org/sites/default/files/resources/ reconceptualizing_and_repositioning.pdf.

Marope, M., Griffin, P., \& Gallagher, C. (2017). Future competences and the future of curriculum. Geneva: IBE UNESCO. Retrieved May 14, 2021, from http://www.ibe.unesco.org/sites/default/files/ resources/future_competences_and_the_future_of_curriculum.pdf.

New Zealand Ministry of Education. (2015). The New Zealand Curriculum. Retrieved May 14, 2021, from https://nzcurriculum.tki.org.nz/content/download/1108/11989/file/NZ\%20Curriculum\% 20Web.pdf.

OECD. (2014). Improving schools in Wales: An OECD perspective. OECD.

Oelkers, J. \& Klee, S. L. (2007). The marginalisation of aesthetic education in school curriculum. In A. Benovot, \& C. Braslavsky (Eds.), School subject knowledge in comparative and historical perspective: Changing curricula in primary and secondary education (pp. 105-118). Dordrecht: Springer.

Pantić, N. (2017). An exploratory study of teacher agency for social justice. Teaching and Teacher Education, 66, 219-230.

Pietarinen, J., Pyhältö, K., \& Soini, T. (2016). Teacher's professional agency—A relational approach to teacher learning. Learning, Research and Practice, 2(2), 112-129.

Power, S., Newton, N., \& Taylor, C. (2020). 'Successful futures' for all in Wales? The challenges of curriculum reform for addressing educational inequalities. The Curriculum Journal. https://doi.org/10. $1002 /$ curj.39

Priestley, M., Biesta, G., \& Robinson, S. (2015). Teacher agency: An ecological approach. Bloomsbury.

Priestley, M., \& Minty, S. (2013). Curriculum for excellence: 'A brilliant idea, but...' Scottish Educational Review, 45(1), 39-52.

Priestley, M., \& Philippou, S. (2018). Curriculum making as social practice: Complex webs of enactment. The Curriculum Journal, 29(2), 151-158.

Pyhältö, K. (2014). Comprehensive school teachers' professional agency in large-scale educational change. Journal of Educational Change, 15, 303-325.

Pyhältö, K., Pietarinen, J., \& Soini, T. (2012). Do comprehension school teachers perceive themselves as active professional agents in school reforms? Journal of Educational Change, 13, 95-116.

Rees, G. \& Taylor, C. (2013). Is there a 'crisis' in Welsh education? Cardiff: WISERD. Retrieved March 20, 2020 from https://wiserd.ac.uk/publications/there-crisis-welsh-education.

Welsh Government. (2015). Pioneer schools. Retrieved May 6, 2020 from https://dera.ioe.ac.uk/23418/2/ 150630-pioneer-schools-e_Redacted.pdf. 
Welsh Government. (2019). A guide to curriculum for Wales 2022. Retrieved April 20, 2020 from https:// hwb.gov.wales/draft-curriculum-for-wales-2022/a-guide-to-curriculum-for-wales-2022\#what-matte rs-in-curriculum-for-wales-2022.

Publisher's Note Springer Nature remains neutral with regard to jurisdictional claims in published maps and institutional affiliations. 